\title{
ARRECADAÇÃO EM TEMPOS DE PANDEMIA: A INSTITUIÇÃO DE EMPRÉSTIMOS COMPULSÓRIOS SOBRE A RENDA DOS TEMPLOS DE QUALQUER CULTO
}

\author{
Renato Bernardi ${ }^{1}$ \\ Raquel de Naday Di Creddo ${ }^{2}$
}

RESUMO: Este trabalho propõe uma solução ao problema da arrecadação tributária em razão dos gastos públicos realizados durante o estado de pandemia. Usando do método hipotéticodedutivo, a pesquisa revela a hipótese de instituição de empréstimo compulsório sobre a renda dos templos religiosos como alternativa viável. Para tanto, a primeira seção destaca os impactos causados pela pandemia na arrecadação tributária. A segunda seção busca as estratégias econômico-tributárias sugeridas e empregadas para a superação da crise arrecadatória e, a terceira seção propõe a instituição de empréstimo compulsório sobre a renda dos templos religiosos, visando o incremento da arrecadação.

PALAVRAS-CHAVE: Pandemia; Arrecadação; Tributação; Empréstimo compulsório; Imunidade.

\section{COLLECTION IN TIMES OF PANDEMIC: THE INSTITUTION OF COMPULSORY LOANS ON THE INCOME OF THE TEMPLES OF ANY CULT}

ABSTRACT: This work proposes a solution to the problem tributary tax due to public spending during pandemic state. Using the hypothetical - deductive method, the research reveals the hypothesis of a compulsory loan institution on the income of religious temples as a viable alternative. For this, the first section highlights the impacts caused by the pandemic on tax collection. The second section seeks the economic and tax strategies suggested and employed

\footnotetext{
${ }^{1}$ Doutor em Direito do Estado (sub-área Direito Tributário) pela Pontifícia Universidade Católica de São Paulo. Professor efetivo dos cursos de Bacharelado, Mestrado e Doutorado, do Curso de Direito do CCSA - UENP, Campus de Jacarezinho. Líder do Grupo de Estudos e Pesquisa "Intervenção do Estado na Vida das Pessoas INTERVEPES” (UENP). Coordenador Pedagógico do PROJURIS Estudos Jurídicos Ltda. Procurador do Estado de São Paulo. E-mail: bernardi@uenp.edu.br.

${ }^{2}$ Mestre em Ciências Jurídicas pela Universidade Estadual do Norte do Paraná (UENP). Participante do grupo de estudos e pesquisa "Intervenção do Estado na Vida das Pessoas - INTERVEPES" (UENP). E-mail: raquel.dicreddo@gmail.com.
} 
to overcome the tax collection crisis and, the third section proposes the institution of compulsory loan on the income of religious temples, aiming at increasing tax.

KEYWORDS: Pandemic; Collection; Taxation; Compulsory loan; Immunity. INTRODUÇÃO

Ao final de 2019, o mundo começou a acompanhar, não sem espanto, notícias que relatavam a contaminação rápida da população de Wuhan, província chinesa, por um vírus até então desconhecido, causador de sintomas semelhantes à Síndrome Respiratória Aguda Grave.

Após pesquisas, um novo coronavírus foi descoberto: o SARS-CoV-2, causador da COVID-19. A doença foi reconhecida pela OMS como "Emergência de Saúde Pública de Importância Internacional" (OPAS, 2020) e o Governo Federal declarou, em fevereiro de 2020, pela Portaria $n^{\circ}$ 188/2020, situação de emergência no Brasil.

No mês seguinte, a Organização Mundial da Saúde (OMS) declarou a COVID-19 como uma pandemia e o Congresso Brasileiro decretou estado de calamidade pública no Brasil, com efeitos até 31/12/2020 (Decreto Legislativo no 06 de 20/03/2020).

O que poderia ser considerado como postura açodada do Ministério da Saúde, Governo Federal e Congresso Nacional tinha, na verdade, o objetivo de preparar e, quiçá, estruturar o país para os impactos sociais e econômicos que poderiam advir, ao exemplo da realidade vivida por outros países, mormente pela Itália.

Com essa estratégia, a ampliação não prevista das aquisições de produtos laboratoriais, de proteção, médicos, hospitalares e sanitizantes, bem como as contratações emergenciais de novos profissionais da área da saúde alçaria justificativa orçamentária.

Apesar de o Ministério da Saúde, com esteio nas orientações da OMS, ter regulamentado, por meio da Portaria $n^{\circ} 356 / 2020$, a realização da quarentena e isolamento social, no mesmo período o Governo Federal lançou uma campanha intitulada "O Brasil não pode parar".

Nessa contradição de ações, o Governo Federal demonstra o seu temor da ocorrência de graves problemas econômicos, insiste no prosseguimento das atividades laborais e, em discurso (15 MINUTOS - GAZETA DO POVO, 2020), o Presidente da República clama que a quarentena seja restrita apenas às pessoas consideradas incluídas em grupos de risco, deixando a população economicamente ativa em seus postos de trabalho. 
Não obstante a divulgação das mensagens, o Poder Executivo não conseguiu evitar que a crise econômica mundial decorrente da pandemia chegasse ao Brasil e reconheceu a necessidade de implementação de medidas para redução dos impactos da pandemia em diversos setores, inclusive no econômico-tributário, objeto de grande preocupação da atual gestão.

Dentre as ações econômicas, divulgadas na página oficial do Ministério da Economia (2020) estão o apoio ao setor produtivo, programa de manutenção do emprego e da renda e, também, tributárias.

Por mais necessárias que as medidas sejam para garantia da dignidade humana, além da necessária salvaguarda da economia, promovem um rápido esvaziamento dos cofres públicos e prejudicam a realização de projetos e programas anteriormente previstos, isso porque as demandas existentes antes da pandemia a ela se acumulam e não podem ser ignoradas.

Essa realidade, por sua vez, deixa evidente a necessidade de se estruturarem novas formas de incremento da arrecadação para fazer frente aos gastos gerados pela pandemia e também para não descobrir as demais necessidades anteriormente reconhecidas.

Os tributos, medidas compulsórias de arrecadação de verbas públicas, têm justamente o objetivo originário de custear as políticas públicas que possibilitem a vida humana e digna em sociedade.

A Justiça Fiscal se insere nesse contexto em razão da realização, pela Administração Pública, da distribuição de renda e da promoção de políticas públicas que realizem os interesses sociais, especialmente em um momento tão sui generis como é o pandêmico, mas também leve em consideração os princípios tributários ao instituir novas formas de auferir receitas, sem que o peso da contribuição esteja concentrado nos setores e classes econômicos já sobrecarregados.

Para tanto, a problemática desta pesquisa está na necessidade de incremento da arrecadação para fazer frente aos gastos gerados pela pandemia, sendo que as medidas tributárias e seus reflexos são pensados como instrumentos para superação desse impasse.

Ante a percepção de lacunas na forma como a arrecadação tributária vem sendo realizada até então, aplica-se o método hipotético-dedutivo para supri-las no atual período, com considerável presteza e sem a necessidade de realização de ampla reforma tributária.

Por este prisma, a primeira seção tem por objetivo expor informações que evidenciam os impactos causados na arrecadação tributária pela pandemia de COVID-19. Por conseguinte, a segunda seção abordará as estratégias econômico-tributárias para superação da crise arrecadatória. Na terceira, e última, seção a pesquisa dedicar-se-á ao estudo da viabilidade da 
instituição de empréstimo compulsório sobre os templos de qualquer culto, como forma de ampliar a arrecadação tributária e angariar fundos para os cofres públicos.

\section{A PANDEMIA DE COVID-19 E SEUS IMPACTOS NA ARRECADAÇÃO TRIBUTÁRIA}

A contaminação de seres humanos por um novo vírus culminou em uma disseminação sem controle no mundo globalizado. E esse mesmo contexto gera uma corrida por recursos e insumos de todas as naturezas para evitar ou minorar os efeitos do contágio.

Com as orientações médico-sanitárias para a realização de quarentenas e isolamento social como formas de auxílio na contenção do espalhamento do vírus SARS-CoV-2, muito dinheiro deixou de circular em razão da queda da atividade econômica e, consequentemente, houve perda de renda e riqueza nas várias camadas sociais de todo o mundo.

No Brasil não foi diferente e as circunstâncias sanitárias impostas como uma necessidade de saúde causaram uma avalanche de reflexos no setor econômico e, consequentemente, fiscal.

Com a crise do coronavírus, a arrecadação, refletindo a profunda contração esperada da atividade econômica, deverá declinar acentuadamente e os gastos extraordinários destinados à saúde e às transferências de renda para pessoas levarão a um forte aumento do déficit primário (IPEA, 2020, p. 7)

Com o intuito de contribuir com a política tributária dos países afetados pela pandemia de coronavírus, a Organização para a Cooperação e Desenvolvimento Econômico (OCDE) editou estudos referenciais para enfrentamento da crise, tratando o problema em quatro etapas (OECD, 2020, p. 4-5)

O primeiro deles identifica-se como "período de contenção e mitigação da pandemia" e sugere a prorrogação de prazos para pagamento de tributos e entrega de declarações, rápida restituição dos tributos, parcelamentos flexíveis de débitos, isenções, compensações (CAMARA..., 2020, p. 15).

No mesmo sentido, defendem Ferreira Neto e Ravanello (2020, p. 542): “medidas mais enérgicas para tal cenário de crise serão necessárias e mais eficazes” e, para tanto, Afonso (2020, p.4) sugere que medidas típicas de estado de guerra sejam adotadas, como requisições de bens e serviços ou então a combinação de intervenções com os regimes extraordinários fiscal e socioconômico. 
O passo neste sentido foi dado com a promulgação da Emenda Constitucional $n^{\circ}$ 106/2020, apelidada de "PEC do orçamento de guerra" (BRASIL, 2020) que institui regime extraordinário fiscal, financeiro e de contratações para enfrentamento da pandemia.

Ao que parece, a equipe econômica do Governo seguiu a primeira etapa dessa cartilha para garantir a permanência da capacidade econômica da população e das empresas e evitar ainda mais danos dessa crise drástica. O Estado compôs planos de apoio ao setor produtivo, operacionalizou a concessão de auxílio emergencial aos trabalhadores informais, instituiu projetos para manutenção do emprego e da renda e ainda estabeleceu mudanças no sistema tributário.

Apesar da necessidade de adoção dessas medidas, em primeiro momento para salvaguarda do impacto causado com a chegada do vírus ao país, verifica-se sua realização de forma descoordenada, evidenciando a total ausência de planejamento para crises no Governo brasileiro, que atua, nesta primeira etapa, apenas para minorar seus efeitos negativos advindos da pandemia.

[...], a política fiscal, no sentido tradicional de expansão do gasto público e/ou redução de impostos, dadas as defasagens envolvidas, pode não ser muito eficiente para lidar com o choque atual no sentido de poder revertê-lo, mas será certamente importante para amenizar seus efeitos, especialmente para a população mais carente e a mais vulnerável, e para pavimentar o caminho de uma possível recuperação rápida (em V) (IPEA, 2020, p. 4)

Mesmo não se tratando de condição ideal, as providências se mostraram relevantes para aplacar os impactos humanitários, sociais e econômicos de uma doença desconhecida, contra a qual se luta, figuradamente, sem armas adequadas. Todavia, não parece possível estar inserido em um contexto pandêmico e sair dele sem cicatrizes.

Sem querer de nenhuma forma desprezar a importância dessas medidas restritivas, mostra-se evidente e incontroverso que essas determinações estatais provocarão algumas consequências negativas de ordem social e econômica (muitas delas, inclusive, já começam a mostrar os seus efeitos perversos em determinados países), podendo-se aqui citar, exemplificativamente: recessão, inflação, aumento expressivo no desemprego, falta de recursos públicos para custear serviços públicos fundamentais, endividamento público e privado fora de controle, dentre outros (FERREIRA NETO; RAVANELLO, 2020, p. 535)

Dentre as operações anunciadas que impactam diretamente a arrecadação estão a suspensão temporária, bem como o elastecimento do prazo para pagamentos de tributos sem a incidência de juros; redução de percentual de alíquotas tributárias, com destaque à redução a zero das alíquotas de importação de produtos de uso médico-hospitalar e do IOF sobre 
operações de crédito; prorrogação do prazo para entrega das declarações do IRPF, sem alteração nas datas de restituição.

Para se ter ideia do que isso representa em redução de arrecadação fiscal, o portal impostômetro, medidor estatístico que compila dados sobre os impostos pagos no Brasil, registrou uma arrecadação aproximada de 917 bilhões de reais em tributos no período compreendido entre 15/03/2020 a 01/09/2020. Todavia, nesse mesmo período no ano de 2019, a arrecadação foi aproximadamente de um trilhão e 112 bilhões de reais, o que revela uma queda aproximada de 195 bilhões na arrecadação (ASSOCIAÇÃO..., 2020).

Os efeitos da crise causada pela pandemia do novo coronavírus levaram o governo brasileiro a ter a menor arrecadação de tributos em 14 anos. Em abril, foram arrecadados 101,2 bilhões de reais, uma queda forte de $29 \%$ sobre o mesmo período de 2019 e o pior resultado para o mês desde 2006, de acordo com os dados divulgados nesta quinta-feira, 21, pela Receita Federal (KIANEK, 2020).

Como confirmação dessa tese, os estudos realizados por Fujiwara, Chropacz, e Offmann (2020) e Borges (2020), utilizando o método exploratório e a pesquisa qualitativa, em resumo, revelaram que, de fato, a pandemia de COVID-19 causou grande impacto na arrecadação tributária dos entes públicos e as consequências são tão mais negativas quanto pior for a trajetória anterior à crise.

\footnotetext{
As condições de sensibilidade ou vulnerabilidade econômica dos países dependem não apenas dos efeitos de contágio humano na geração de expectativas em determinada economia nacional, mas antes dependem das trajetórias econômicas preexistentes à crise, bem como do comportamento volátil do mercado financeiro nacional e da regularização dos ciclos econômicos produtivos. (SENHORAS, 2020, p.39)
}

Ainda que a pandemia não tenha chegado ao seu fim, seus efeitos até aqui impingiram queda na arrecadação tributária brasileira, mormente em razão da inexistência de estratégias previamente traçadas para situações de crise.

Com esse parâmetro, o fortalecimento de ideias de superação da crise com novas estratégias de arrecadação passa a ser um imperativo na busca do equilíbrio financeiro do Estado.

2. ESTRATÉGIAS ECONÔMICO-TRIBUTÁRIAS PARA SUPERAÇÃO DA CRISE ARRECADATÓRIA

O contexto de queda na arrecadação decorrente da pandemia de COVID-19 e das ações necessariamente aplicadas pelo Estado provocam intensa movimentação política, econômica e 
até mesmo acadêmica em prol de soluções que visem a recuperação da receita aos cofres públicos.

De forma orientativa, a carta de conjuntura do Ipea publicada no primeiro trimestre de 2020 traz uma observação para o estudo da política fiscal merecedora de destaque:

É importante que a política fiscal focalize nos mais necessitados e que seja calibrada
de modo a não impedir o reerguimento da economia após a crise. A regra do teto é a
âncora de política fiscal que permitiu a obtenção do equilíbrio macroeconômico e a
redução da taxa de juros para o menor patamar da história do país. Nesse sentido, ela
precisa ser preservada para garantir o equilíbrio macroeconômico e o bem-estar da
população no longo prazo (IPEA, 2020, p. 8).

De acordo com o estudo divulgado pela $\operatorname{OECD}$ (2020, p. 42), os tributos terão papel fundamental na restauração das finanças públicas, tanto em relação às receitas, quanto da estrutura fiscal, que poderá ser adaptada ao período pós-COVID. Todavia, é importante que os atores políticos considerem o apoio ao crescimento sólido como forma de aumentar as receitas fiscais.

No Brasil, visando, supostamente, a salvaguardar a arrecadação no período de recuperação da crise gerada pela pandemia, o Ministério da Economia apresentou projetos para Reforma Administrativa (Projeto de Emenda à Constituição ${ }^{\circ}$ 32/2020) e para Reforma Tributária (Projeto de Lei no 3887/2020).

Porém, é preciso lembrar que tais medidas já eram uma proposta da campanha política do atual governo e sua apresentação neste cenário, que reclama ações rápidas por parte do Poder Legislativo, deve ser vista com cautela.

Ao que parece, o que eram intenções de campanha tornaram-se projetos redigidos às pressas, sem observar as necessidades peculiares do momento pandêmico, sendo caso de se questionar se uma sobrecarga de tributação em face aos contribuintes já sobrecarregados não tende a causar um efeito inverso ao previsto.

Com essa imposição, mesmo após o fim da pandemia os efeitos decorrentes das supramencionadas reformas hão de permanecer como parte ordinária da estrutura tributária do Estado e não como estratégia de arrecadação em situação de crise.

$\mathrm{Na}$ esteira do pensamento de Ferreira Neto e Ravanello (2020, p. 535), a implementação de políticas públicas contingenciais faz surgir dilemas que reclamam a adoção de novas fórmulas para solucionar o problema do equilíbrio dos cofres públicos, visando superar as conhecidas até então.

Temos, pois, uma espécie de crise pandêmica (rectius, paradigmática) ocorrendo também no universo jurídico, a qual está obrigando a uma profunda revisão crítica de 
algumas noções dogmáticas encrustadas no pensamento técnico e cultural do operador do direito [...]. (FERREIRA NETO; RAVANELLO, 2020, p. 535)

Sendo um momento excepcional, há um reclamo por soluções de igual natureza, sob pena de se onerar desnecessariamente a população com o fim da pandemia.

Nesse sentido,

[...] medidas de política fiscal de caráter permanente, que resultem em alta de gastos obrigatórios devem ser evitadas para não colocar em risco o equilíbrio macroeconômico de longo prazo, que poderia prejudicar a recuperação econômica prevista neste texto e poderia gerar custos muito altos em termos de perda de renda $\mathrm{e}$ emprego (IPEA, 2020, p. 2)

Teoricamente, o que se vislumbra como ideal é a implementação de medidas fiscais extraordinárias para fazer frente à condição excepcional. Desse modo, "é preciso criar urgentemente um conjunto de regras fiscais e contas públicas que integrem um regime extraordinário e apartado do ordinário (que precisa continuar sendo aplicado a tudo aquilo que não esteja envolvido no esforço de guerra)" (AFONSO, 2020, P. 1).

Como sugestões de soluções excepcionais, a OECD (2020, p. 42-43) relaciona, por exemplo, a tributação especial sobre eventuais aumentos de ganhos durante a pandemia, a instituição de normativas fiscais sobre o preço do carbono, a consideração de bases fiscais novas e subutilizadas e tributação diferenciada a empresas multinacionais.

Nessa toada de excepcionalidade, segundo a Agência Senado (2020) dois projetos de tributação sobre grandes fortunas foram apresentados após o início da pandemia. Um deles, de autoria da Senadora Eliziana Gama (PLP 50/2020) (SENADO, 2020) sugere a instituição de empréstimos compulsórios aplicado às grandes fortunas, pois poderia gerar efeitos imediatos.

Pautado na necessidade de resolver o problema da arrecadação em tempos de pandemia e levando em consideração as orientações da OECD e das literaturas utilizadas acerca da primordialidade da instituição de soluções excepcionais, vislumbra-se uma hipótese de solução com a instituição de empréstimos compulsórios sobre os templos de qualquer culto, como providência viável e rápida

\section{A VIABILIDADE DA INSTITUIÇÃO DE EMPRÉSTIMO COMPULSÓRIO SOBRE OS TEMPLOS DE QUALQUER CULTO}

Ainda que diante de um contexto pandêmico, é relevante ter em mente que o dever de pagar tributos é uma consequência decorrente do formato social democrático escolhido para vida em coletividade, com concentração de poderes pelo Estado. 
A relação entre direitos fundamentais, políticas públicas e pagamento de tributos é indissociável, uma vez que o gozo de muitos direitos fundamentais passa pela realização de políticas públicas promovidas pelo Estado. Estas, por sua vez, só podem ser realizadas se houver recursos financeiros para tanto, o que, via de regra, se obtém por meio da atividade de tributação do Estado (DI CREDDO, 2012, p. 194-195).

O pagamento de tributos garante a existência do orçamento público, e como ensina Afonso (2020, p.1), esse orçamento precisa de um delineamento ordinário "voltado para as despesas correntes e manutenção da máquina pública" e de um delineamento de capital, "focado em gerenciamento da demanda".

O Constituinte de 1988, quando estabeleceu as espécies tributárias no título VI da Carta Magna, relacionou os tributos a serem empregados ordinariamente (impostos, taxas e contribuição de melhoria) e ainda relacionou duas hipóteses tributárias a serem lançadas em situações de exceção (imposto extraordinário de guerra e empréstimos compulsórios).

Com isso fica claro que o texto constitucional já prevê ferramentas a serem empregadas na superação de crises, sem a necessidade de reformas aviltantes, irrefletidas e ilegítimas.

Seguindo a linha dos tributos constitucionais da excepcionalidade, o artigo 148, traz a possibilidade de a União instituir, por Lei Complementar, empréstimos compulsórios para atendimento de situações emergenciais.

O empréstimo compulsório é uma ferramenta que a Constituição permite em circunstâncias emergenciais, como guerras ou calamidades públicas. A crise provocada pelo novo coronavírus provocou a decretação de estado de calamidade no país até 31 de dezembro, abrindo caminho para essa possibilidade. Ao contrário dos impostos, o empréstimo compulsório não precisa aguardar o ano seguinte para começar a valer. No entanto, os valores arrecadados devem ser devolvidos no futuro (AGÉNCIA SENADO, 2020, n.p.)

As situações que tal espécie tributária resguarda se referem ao atendimento das despesas extraordinárias, decorrentes de calamidade pública, guerra externa ou sua iminência, ou ainda como forma de investimento público de caráter urgente e de relevante interesse social, observando-se as ressalvas quanto ao princípio da anterioridade tributária.

Art. 148. A União, mediante lei complementar, poderá instituir empréstimos compulsórios:

I - para atender a despesas extraordinárias, decorrentes de calamidade pública, de guerra externa ou sua iminência;

II - no caso de investimento público de caráter urgente e de relevante interesse nacional, observado o disposto no art. 150, III, "b".

Parágrafo único. A aplicação dos recursos provenientes de empréstimo compulsório será vinculada à despesa que fundamentou sua instituição (BRASIL, 1988). 
A conjuntura socioeconômica em que o Brasil está atualmente inserido satisfaz tanto os requisitos do inciso I, do artigo 148, da Constituição Federal, ante a situação de calamidade pública decretada em razão da COVID-19, como também do inciso II, haja vista os investimentos públicos necessários nesse momento, quer para a aquisição de bens e produtos, quer para o pagamento dos auxílios emergenciais, e também para recomposição da saúde financeira do próprio Estado.

Estando clara a conjuntura nacional passível de instituição de empréstimos compulsórios, resta agora analisar sua incidência para além das grandes fortunas, já proposta no Senado. Com base nos dispositivos constitucionais, verifica-se a possibilidade de instituição dos empréstimos também sobre os templos de qualquer culto.

A análise de tal viabilidade se dá a partir do inciso VI do artigo 150 da Constituição Federal que prevê imunidades tributárias em relação a entes, entidades e objetos específicos e, como destaca Roque Carraza (2012, p. 3), as normas imunizantes revelam a proteção constitucional a interesses e valores fundamentais da sociedade.

Dentre as hipóteses de imunidade, está a proibição de instituir impostos sobre os templos de qualquer culto e a ponderação de Carraza leva à inferência de que, para o Constituinte originário, a liberdade de crença religiosa e o livre exercício de cultos são pilares da dignidade da pessoa humana e devem ser garantidos até mesmo em face da arrecadação para o próprio Estado.

Chiesa argumenta que (2019) "a imunidade tem como propósito garantir que a tributação por meio de impostos não se constitua em entrave ao livre exercício da atividade religiosa", de modo que a "norma desonerativa garante que não haverá ingerência do Estado nas religiões pela via da tributação, proibindo-se a instituição de impostos que possam resultar em entraves ao seu funcionamento" (NASPOLINI, 2018, p. 123).

\footnotetext{
A imunidade tributária dos templos veda a arrecadação de qualquer imposto sobre as entidades que, ao desenvolverem suas atividades, exercem o direito fundamental à liberdade religiosa. Como não objetivam lucros e, muitas vezes, são desprovidas de recursos, a tributação dessas entidades configuraria uma ofensa aos objetivos e fins da Constituição que defende e preserva a liberdade em todas as suas formas (KUMMER e GARCIA, 2016, p. 101)
}

Essa perspectiva, todavia, pode levar a duas ilações: a primeira de que o estabelecimento de qualquer tributo ofende a liberdade de crença religiosa e o livre exercício de cultos; a segunda de que o Constituinte originário deliberadamente estabeleceu que apenas 
a instituição de impostos fere a liberdade de crença e de culto e o mesmo não acontece com os demais tributos, em razão da natureza jurídica de cada espécie tributária.

Ao que parece, o atual Presidente da República já se posicionou favoravelmente à primeira corrente e alegou que pretende enviar uma proposta de emenda à Constituição (PEC), antes do mês de outubro de 2020, visando conceder imunidade total às Igrejas (ESTADÃO, 2020).

Todavia, em um período de calamidade pública, em que os servidores dos setores econômico-tributário do governo se debruçam para estabelecer novas formas de arrecadação para os cofres públicos, as propostas de renúncia de receita com imunidade total ou imunidade e isenção total de tributos não aparentam ser as mais adequadas.

O entendimento que prevalece na atualidade em relação a alínea " $b$ " do art. 150, inciso VI da Constituição Federal (1988) é o da interpretação literal em que se veda, unicamente, a instituição de impostos sobre os templos de qualquer culto, não alcançando as demais espécies tributárias.

TRIBUTÁRIO. OMISSÃO, OBSCURIDADE, CONTRADIÇÃO E/OU ERRO. ARTIGO 1.022 DO CPC/2015. INEXISTÊNCIA. TENTATIVA DE REAPRECIAÇÃO DA CAUSA. FUNDAMENTAÇÃO PER RELATIONEM. ADMISSIBILIDADE. EMBARGOS DE DECLARAÇÃO DESPROVIDOS. 1. Sabe-se que os embargos de declaração, segundo a norma do art. 1.022 do CPC, são recurso de fundamentação vinculada, restrito a situações em que é manifesta a incidência do julgado em obscuridade, contradição ou omissão, admitindo-se também a utilização para a correção de inexatidões materiais e, ainda, com um pouco mais de liberalidade, para reconsideração ou reforma de decisões manifestamente equivocadas. [...] 3. Na hipótese, sustenta a embargante que o acórdão embargado incorreu em omissão ao deixar de considerar que as imunidades são vedações absolutas ao poder de tributar, tendo sido colocadas como forma de implementar as finalidades prestigiadas pela Constituição, e que não há fato gerador passível de tributação uma vez que a ora embargante é instituição religiosa, sem fins lucrativos, razão pela qual não registra lucro. 4. Ocorre que o voto condutor do acórdão é claro ao afirmar que a única pessoa jurídica que possui imunidade sobre as contribuições sociais são as entidades beneficentes de assistência social e que atendem os requisitos exigidos em lei, conforme art. $195, \$ 7^{\circ}$, da Constituição Federal. Aduz, ainda, que para fins de CSLL, o lucro corresponde ao resultado econômico positivo da pessoa jurídica que, no caso particular, é representado pelo superávit da entidade religiosa, com as deduções aplicáveis pela legislação tributária. 5. Vê-se, à evidência, que a recorrente demonstra mero inconformismo com o julgado, e não chega a apontar, objetivamente, qualquer omissão, obscuridade, contradição e/ou erro, capazes de autorizar o manejo da via eleita. Aliás, pretende, tão somente, rediscutir a matéria sob outros argumentos. [...]. 9. Embargos de declaração desprovidos (APELAÇÃO CÍVEL, 2020, grifo nosso)

Não estão exonerados os demais tributos, diversos dos impostos, que incidirão normalmente. Ou seja, não se aplica às taxas, à contribuição de melhoria, às contribuições sociais e aos empréstimos compulsórios. 
No caso das taxas, são cobradas em decorrência da prestação direta de um serviço público específico e divisível, cuja base de cálculo em hipótese alguma se confunde com a dos impostos, não sendo minimamente coerente conceber que toda a sociedade arque com os serviços prestados a uma entidade religiosa. A mesma ideia se aplica às contribuições, que compreendem uma contraprestação a atuação estatal, com uma circunstância intermediária, como as contribuições sociais ou contribuições sobre o lucro líquido.

Levando em consideração esta corrente, o empréstimo compulsório, pode ser considerado constitucionalmente viável de instituição em relação aos templos de qualquer culto, não ferindo a liberdade de culto em razão da natureza jurídica do aludido tributo.

Não cabe aqui, justificar a impossibilidade da instituição de empréstimo compulsório sobre os templos de qualquer culto com a ratio legis da imunidade constitucional.

Pois, "uma das formas que o Estado estabeleceu para não criar embaraços à prática religiosa foi outorgar imunidade aos templos onde se realizem os respectivos cultos" (STF, RE 562.351, 2012). A imunidade está, portanto, a serviço da liberdade de crença e da garantia de livre exercício dos cultos religiosos, assegurada proteção aos locais de culto e às suas liturgias, conforme se colhe do art. 5, VI, da CF (1988), mas suas garantias devem ser considerados dentro do espectro de limitação constitucional.

As religiões podem ser consideradas como de interesse social e de função muito importante para a vida de grande parte dos brasileiros, tanto que, de acordo com o Censo Demográfico de 2010, do Instituto Brasileiro de Geografia e Estatística (IBGE, 2012, p.91), 92\% da população do País segue alguma religião.

Além disso, as entidades religiosas são organizações sem fins lucrativos e que, teoricamente, não comercializam produtos ou vendem serviços, portanto a imunidade dos impostos estimula a permanência e expansão de religiões no País. Do contrário - caso fossem amplamente tributadas-, determinadas entidades religiosas sofreriam grandes dificuldades financeiras, o que poderia levar à extinção de tais instituições, o que não se pretende.

Desde há muito assenta-se pacífico que a liberdade de culto é uma cláusula pétrea, pois tem previsão no texto constitucional no seu artigo $5^{\circ}$., VI, sendo a imunidade religiosa uma das garantidoras desse direito pétreo.

Partindo-se, então, do pressuposto de que a imunidade religiosa é cláusula garantidora da liberdade de culto, fica claro que a instituição de empréstimo compulsório sobre os templos 
de qualquer culto, além de não contrariar a norma imunizante do art. 150, inciso VI, alínea "b", da Constituição Federal, também não tem o condão para atentar contra a liberdade de culto, já que por se tratar de espécie tributária restituível, a entidade religiosa poderá repetir todo o valor pago a título do empréstimo compulsório, que pode ser chamado de "pandêmico", hipótese de pesquisa do presente artigo.

Trata-se de um tributo restituível. O próprio termo "empréstimo", já pressupõe tal condição, uma vez que de acordo com o seu conceito jurídico, refere-se a um contrato em que uma das partes recebe, para uso ou utilização, uma coisa que, depois de certo tempo, deve restituir ou dar outra do mesmo gênero, quantidade ou qualidade.

Caracteriza-se assim por ser uma cessão temporária do uso e gozo de determinada coisa (fungível ou infungível) a um contratante que, ao recebê-la, contrai a obrigação de restituíla, no prazo legal ou contratual. É dividido em duas modalidades: a) comodato, empréstimo de coisa não fungível, que não pode ser substituída por outra e, b) mútuo; empréstimo de coisa fungível, que pode ser substituída por outra do mesmo gênero, qualidade e quantidade.

Quando do pagamento do empréstimo compulsório, incide a norma que, prevendo a sua restituição, gera direito subjetivo do contribuinte a tal prestação futura. Uma nova lei não pode suprimir esse direito, sob pena de ofensa ao art. $5^{\circ}$, XXXVI, da Constituição Federal (1988), que garante o direito adquirido, dizendo que a lei não o prejudicará.

Ademais, a restituição deve ser em moeda. Isso porque já decidiu o STF:

utilizando-se, para definir o instituto de direito público, do termo empréstimo [...], a Constituição vinculou o legislador à essencialidade da restituição na mesma espécie, seja por força do princípio explícito do art. 110 do CTN, ou seja porque a identidade do objeto das prestações recíprocas é indissociável da significação jurídica e vulgar do vocábulo [...] (STF, RE 121.336, 1992)

Se, por um lado, a garantia de devolução do valor recolhido pode assegurar os interesses dos templos religiosos, por outro, fato também a recomendar a instituição de tal espécie tributária em tempos de pandemia, está a agilidade da transposição dos valores dos cofres dos templos ao erário público, já que o empréstimo compulsório a ser instituído para fazer frente a uma situação de calamidade não se submete às anterioridades de exercício e nonagesimal, nos termos do disposto no $\S 1^{\circ}$, do art. 150, da CF (1988).

Finalmente, vale observar que o tipo de fato gerador não é especificado pelo texto constitucional, podendo ser vinculado ou não vinculado. Assim, tanto o consumo de energia elétrica, de combustível ou a propriedade de aeronave ou embarcação, podem ser fatos geradores.

Revista de Direito Tributário e Financeiro | e-ISSN: 2526-0138 | Encontro Virtual | v. 6 | n. 2 | p. 60 - 78 | Jul/Dez. 2020. 
No caso ora em estudo, sugere-se que o fato gerador do empréstimo compulsório a ser instituído sobre os tempos de qualquer culto, para fazer frente a uma situação de calamidade gerada pela pandemia de COVID-19, seja a renda obtida pelas entidades religiosas, fixando-se alíquota capaz de respeitar os princípios da capacidade contributiva e do não confisco.

\section{CONSIDERAÇÕES FINAIS}

A pandemia do novo coronavírus provocou queda na atividade econômica sem precedentes na história mundial recente. Estimativas da OCDE preveem que a produção pode inicialmente cair entre $20 \%$ a $25 \%$, e o consumo das famílias em cerca de um terço em diversos países. Para cada mês de confinamento, calcula-se queda de cerca de $2 \%$ no produto interno bruto (PIB) (OECD, 2020, p. 8).

Em função das medidas de isolamento adotadas, os indicadores econômicos divulgados até o momento apontam forte deterioração da economia brasileira.

Quanto à arrecadação tributária, a Secretaria da Receita Federal do Brasil (RFB, 2020) divulgou que o volume de receitas da União (administradas e não administradas pelo órgão) em abril de 2020 foi de $\mathrm{R} \$ 101.154$ milhões. Isso representa uma queda nominal de 27,2\% em relação ao mesmo mês do ano anterior (R \$ 139.030 milhões). Segundo ao RFB, a explicação para a perda de arrecadação estaria tanto na retração econômica e no aumento das compensações tributárias quanto nas alterações na legislação tributária realizadas para mitigar os efeitos econômicos da pandemia. Destacam-se dentre estas o diferimento no pagamento das contribuições previdenciárias patronais, da contribuição para o Programa de Integração Social e de Formação do Patrimônio do Servidor Público (PIS/Pasep), da contribuição para financiamento da seguridade social (Cofins), do Simples Nacional e das cotas do imposto de renda.

A tributação nasce para prover o bem-comum pela necessidade do homem de associar-se e criar vida política. Ela decorre da disposição do homem de viver em um Estado, dentro da visão Aristotélica de que o Estado é uma instituição natural e a mais ampla das associações humanas. E, nascendo com a finalidade primordial do financiamento do Estado por desejo da coletividade, uma vez instituída, a tributação adquire uma importância abissal apta a financiar as políticas públicas, em especial nos momentos de calamidade excepcional, como o que presenciamos atualmente. 
Nesse pensar, sendo uma situação sócio-econômica imprevisível e imprevista em nível mundial, há que se buscar soluções arrecadadoras inusitadas para fazer frente ao aumento de gasto advindo com a pandemia.

O que o presente trabalho propõe á a instituição de empréstimo compulsório sobre a renda dos templos de qualquer culto, haja vista sua previsão de excepcionalidade pela própria Constituição Federal.

A hipótese não encontra óbice na imunidade religiosa, tem caráter restituível, fato suficiente a garantir a plena liberdade de culto no País e, ainda, não se submete às anterioridades de exercício, nem nonagesimal. A edição de Lei Complementar instituidora é o veículo apto a introduzir referida espécie tributária no cenário jurídico-econômico nacional para fazer frente ao aumento de gastos que têm origem na pandemia de COVID-19.

Por este horizonte, restou demonstrada a viabilidade de utilização de tributação especial constitucionalmente garantida para fazer frente aos gastos públicos decorrentes do estado pandêmico, com incremento da arrecadação.

\section{REFERÊNCIAS BIBLIOGRÁFICAS}

AFONSO, José Roberto. Orçamento de guerra e quarentena fiscal. Revista Conjuntura Econômica, Rio de Janeiro, v. 74, n. 4, p. 24-27, abr. 2020. ISSN 0010-5945. Disponível em: http://bibliotecadigital.fgv.br/ojs/index.php/rce/article/view/81588. Acesso em: 24 Set. 2020

ASSOCIAÇÃO COMERCIAL DE SÃO PAULO. Impostômetro. 2020. Disponível em: https://impostometro.com.br/home/acsp. Acesso em: 19 set. 2020

ATALIBA, Geraldo. Hipótese de incidência tributária. $6^{\mathrm{a}}$ ed. $8^{\mathrm{a}}$ tiragem. São Paulo: Malheiros, 2006. 209 p.

BARIFOUSE, Rafael. Coronavírus: por que governo brasileiro decretou emergência mesmo sem caso confirmado no país. BBC News Brasil, São Paulo, 3 fev. 2020. N.P. Disponível em https://www.bbc.com/portuguese/brasil-51365332. Acesso em 19 set. 2020.

BORGES, Maria Gabriela Barbosa. Impactos da Covid-19 nas Receitas Tributárias e na Condição Financeira dos Estados do Sudeste do Brasil. In: USP INTERNATIONAL CONFERENCE IN ACCOUNTING, 20., 2020, São Paulo. Anais eletrônicos ... São Paulo: Comitê de Organização do USP International Conference in Accounting, 2020, 13p. Disponível em: https://congressousp.fipecafi.org/anais/Anais2020/ArtigosDownload/3010.pdf. Acesso em 25 set. 2020.

BRASIL. Câmara dos Deputados. Estudo técnico: Tributação em tempos de pandemia. Brasília: Câmara dos Deputados, Junho de 2020. 105 p. Disponível em 
https://www2.camara.leg.br/atividade-legislativa/estudos-e-notas-tecnicas/publicacoes-daconsultoria-legislativa/Estudos-e-notas-tecnicas. Acesso em 14 set. 2020.

BRASIL.[ Constituição (1988)]. Constituição da República Federativa do Brasil de 1988. Brasília, DF: Presidência da República, 2020, N. P. Disponível em:

http://www.planalto.gov.br/ccivil_03/constituicao/constituicao.htm. Acesso em 26 set. 2020.

BRASIL. Decreto Legislativo $n^{\circ}$ 06, de 2020: Reconhece, para os fins do art. 65 da Lei $\mathrm{n}^{\circ}$ 101, de 4 de maio de 2000, a ocorrência do estado de calamidade pública, nos termos da solicitação do Presidente da República encaminhada por meio da Mensagem no 93, de 18 de março de 2020. Diário Oficial da União, Brasília/DF: Congresso Nacional, 20 mar. 2020, Edição extra C. Disponível em: https://www.planalto.gov.br/ccivil_03/portaria/dlg62020.htm. Acesso em 22 set 2020.

BRASIL. Emenda Constitucional n ${ }^{\circ}$ 106: Institui regime extraordinário fiscal, financeiro e de contratações para enfrentamento de calamidade pública nacional decorrente de pandemia.

Diário Oficial da União, Brasília, DF, 08 mai. 2020, Edição: 87, Seção: 1, Página: 1. Orgão: Atos do Congresso Nacional. Disponível em https://www.in.gov.br/en/web/dou/-/emendaconstitucional-n-106-255941715. Acesso em 25 set. 2020.

BRASIL. Ministério da Economia. Medidas econômicas voltadas para a redução dos impactos da Covid-19 (Coronavírus) — linha do tempo. N.P. Disponível em: https://www.gov.br/economia/pt-br/centrais-de-conteudo/publicacoes/boletins/covid19/timeline. Acesso em 19 set. 2020

BRASIL. Portaria n ${ }^{\circ}$ 188, de 3 de fevereiro de 2020: Declara Emergência em Saúde Pública de importância Nacional (ESPIN) em decorrência da Infecção Humana pelo novo Coronavírus (2019-nCoV). Diário Oficial da União, Brasília/ DF: Ministério da Saúde, 04 fev. 2020, Edição: 24-A, Seção:1 - Extra, Página: 1. Disponível em: https://www.in.gov.br/web/dou/-/portaria-n-188-de-3-de-fevereiro-de-2020-241408388. Acesso em 17 set. 2020

BRASIL. Portaria n ${ }^{\circ}$ 356, de 11 de março de 2020: Dispõe sobre a regulamentação e operacionalização do disposto na Lei $\mathrm{n}^{\circ} 13.979$, de 6 de fevereiro de 2020, que estabelece as medidas para enfrentamento da emergência de saúde pública de importância internacional decorrente do coronavírus (COVID-19). Diário Oficial da União, Brasília/DF: Ministério da Saúde, 12 mar. 2020, Edição: 49, Seção:1, Página: 185. Disponível em: https://www.in.gov.br/web/dou/-/portaria-n-356-de-11-de-marco-de-2020-247538346. Acesso em 19 set. 2020

BRASIL. Projeto de Lei Complementar, $\mathbf{n}^{\circ} 50$ de 2020:Institui imposto sobre grandes fortunas e empréstimo compulsório, que financiará necessidades de proteção social decorrentes da covid-19. Brasília: Senado Federal, [2020]. Disponível em: https://www25.senado.leg.br/web/atividade/materias/-/materia/141223. Acesso em 25 set. 2020. 
BRASIL. STF. Recurso Extraordinário: RE 562.351. Constitucional. Recurso Extraordinário. Imunidade Tributária. Art. 150, VI, “c”, da Carta Federal. Necessidade de reexame do conjunto fático-probatório. Súmula 279 do STF. Art. 150, VI, "b", da Constituição da República. Abrangência do termo "templos de qualquer culto". Maçonaria. Não configuração. Recurso Extraordinário conhecido em parte e, no que conhecido, desprovido. Recorrente: Grande Oriente do Rio Grande do Sul. Recorrido: Município de Porto Alegre. Relator Min. Ricardo Lewandowski, 04 de setembro de 2012. Disponível em: http://portal.stf.jus.br/processos/detalhe.asp?incidente=2555864. Acesso em 27 set. 2020.

BRASIL. Tribunal Regional Federal da $2^{a}$ Região. Apelação Cível: AC 0132740-

88.2016.4.02.5101. Tributário. Omissão, obscuridade, contradição e/ou erro. Artigo 1.022 do CPC/2015. Inexistência. Tentativa de reapreciação da causa. Fundamentação per relationem. Admissibilidade. Embargos de declaração desprovidos. Apelante:Igreja Internacional da Graça de Deus. Apelado: União Federal/Fazenda Nacional. Relator: Desembargador Federal FERREIRA NEVES, 17 de dezembro de 2019. Disponível em:

https://www10.trf2.jus.br/consultas?movimento=cache\&q=cache:FDdh8-

S4jLMJ:acordaos.trf2.jus.br/apolo/databucket/idx\%3Fprocesso\%3D201651011327400\%26co ddoc\%3D753797\%26datapublic\%3D2020-01-

$10 \% 26$ pagdj\%3D340\%2520e\%2520segs+CSLL+-

+ entidade+religiosa \&site $=\mathrm{v} 2 \_$jurisprudencia\&client $=\mathrm{v} 2 \_$index $\&$ proxystylesheet $=\mathrm{v} 2$ _index $\& 1$ $\mathrm{r}=$ lang_pt\&ie=UTF-8\&output=xml_no_dtd\&access=p\&oe=UTF-8. Acesso em 26 set. 2020.

BRASIL. União Federal. Procuradoria Geral da Fazenda Nacional. Lista de devedores. Disponível em: https://www.listadevedores.pgfn.gov.br/resultado. Acesso em 27 set. 2020.

CARRAZZA, Roque Antonio. A imunidade tributária dos templos de qualquer culto (art. 150, VI, $\boldsymbol{b}$, da CF) - Questões conexas. In:MORETI, Daniel (org); CARRAZA, Elizabeth Nazar (coord.). Imunidades Tributárias. Rio de Janeiro: Elsevier, 2012. P. 1 - 47.

CHIESA, Clélio. Imunidade: Tomo Direito Tributário. Edição 1, Maio de 2019. N.P. Disponível em https://enciclopediajuridica.pucsp.br/verbete/280/edicao-1/imunidade. Acesso em 21 set. 2020

DI CREDDO, Raquel de Naday. O pagamento de tributos e a justiça fiscal. IN. Revista Jurídica da Procuradoria Geral do Estado do Paraná: Direito do Estado em Debate, n. 3. Curitiba: PGE, 2012. P. 189 - 210.

FERNANDES, Adriana; SOARES, Jussara. Apesar das críticas, governo estuda como 'imunizar' igrejas de tributos. Estadão, Brasília, 15 set. 2020 . Seção Economia. N.P. Disponível em https://economia.estadao.com.br/noticias/geral,apesar-das-criticas-governoestuda-como-imunizar-igrejas-de-tributos,70003437954. Acesso em 20 set. 2020

FERREIRA NETO, Arthur Maria; RAVANELLO, Alexandre. Pandemia da Covid-19 e a Flexibilização de Institutos Tributários: a Importância dos Juízos de Equidade em Calamidades Públicas. Revista Direito Tributário Atual, n.45. p. 532-564. São Paulo: IBDT, $2^{\circ}$ semestre 2020. Quadrimestral. ISSN: 1415-8124. Disponível em: https://ibdt.org.br/RDTA/45-2020/pandemia-da-covid-19-e-a-flexibilizacao-de-institutos- 
tributarios-a-importancia-dos-juizos-de-equidade-em-calamidades-publicas/. Acesso em: 17 set. 2020

FOLHA informativa COVID-19. Escritório da OPAS e da OMS no Brasil. N.P. https://www.paho.org/pt/covid19 Acesso em 17. set. 2020

FUJIWARA, Ricardo Shigueru; CHROPACZ, Franciely; OFFMANN, Denis. Administração Tributária Municipal e a Covid-19: Um estudo do impacto nas receitas tributárias e nos serviços públicos. Boletim de Conjuntura (BOCA), Boa Vista, v. 3, n. 8, p. 86-100, ago. 2020. ISSN 2675-1488. Disponível em: https://revista.ufrr.br/boca/article/view/Fujiwara. Acesso em: 25 set. 2020.

\section{INSTITUTO BRASILEIRO DE GEOGRAFIA E ESTATÍSTICA (IBGE). Censo}

Demográfico 2010: Características gerais da população, religião e pessoas com deficiência. Rio de Janeiro: IBGE, 2011. 265 p. Disponível em:

https://biblioteca.ibge.gov.br/index.php/biblioteca-catalogo?view=detalhes\&id=249230.

Acesso em 27 set. 2020

JÚNIOR, José Ronaldo de Castro Souza; LEVY, Paulo Mansur; SANTOS, Francisco Eduardo de Luna e Almeida; CARVALHO, Leonardo Mello de. Carta de Conjuntura, IPEA, número $46,1^{\circ}$ trimestre de 2020 . Visão geral da conjuntura. Disponível em:

https://www.ipea.gov.br/cartadeconjuntura/index.php/2020/03/visao-geral-daconjuntura-6/. Acesso em 24 set. 2020

KIANEK, Alessandra. O rombo bilionário do governo causado pela Covid na arrecadação de tributo. Veja, sem local de publicação, 21 de maio de 2020. Seção Economia. N.P. Disponível em https://veja.abril.com.br/economia/o-rombo-bilionario-do-governo-na-arrecadacao-detributo-causado-pela-covid/. Acesso em 25 set. 2020.

KUMMER, Ana Paula; GARCIA, Rafaella Cruz. A isenção da taxa municipal nos eventos religiosos de Maceió. I Encontro de Pesquisas Judiciárias da Escola Superior da Magistratura do Estado de Alagoas - ENPEJUD: anais [recurso eletrônico]. Alberto Jorge de Barros Lima et. al. (Coords.). Maceió, AL: Escola Superior da Magistratura de Alagoas, FUNDESMAL, 2016. p. 100-112. Disponível em:

http://enpejud.tjal.jus.br/index.php/exmpteste01/article/view/72. Acesso em 26 set. 2020

NASPOLINI, Ludmila Indalencio. A imunidade tributária dos templos e o fenômeno da mercantilização das religiões. 2018. 162f. Dissertação (mestrado) - Programa de Pós Gradução em Direito da Universidade Federal do Rio Grande do Sul. Porto Alegre, 2018. Disponível em https://lume.ufrgs.br/handle/10183/181091. Acesso em 21 set 2020.

OECD. Tax and fiscal policy in response to the Coronavirus crisis: Strengthening confidence and resilience. 49p. Disponível em: https://www.oecd.org/ctp/tax-policy/tax-andfiscal-policy-in-response-to-the-coronavirus-crisis-strengthening-confidence-andresilience.htm. Acesso em: 20 set. 2020. 
PEREIRA, Roger. Mesmo com imunidade tributária, igrejas aparecem entre os maiores devedores da União. Gazeta do Povo, sem local de publicação, 04 de fevereiro de 2020. Seção Vida e Cidadania. N.P. Disponível em https://www.gazetadopovo.com.br/vida-ecidadania/mesmo-com-imunidade-tributaria-igrejas-aparecem-entre-os-maiores-devedoresda-uniao/. Acesso em 27 set. 2020.

RECEITA FEDERAL DO BRASIL (RFB). Análise da Arrecadação das Receitas Federais: Abril/2020. Brasília/DF: Ministério da Economia, 2020. 49p. Disponível em: http://receita.economia.gov.br/dados/receitadata/arrecadacao/relatorios-do-resultado-daarrecadacao/arrecadacao-2020/abril2020/analisemensal-abr-2020.pdf. Acesso em 27 set. 2020.

Senado debate quatro propostas de imposto sobre grandes fortunas. Agência Senado. Brasília, 27 mar. 2020. Seção Projetos. N.P. Disponível em https://www12.senado.leg.br/noticias/materias/2020/03/27/senado-debate-quatro-propostasde-imposto-sobre-grandes-fortunas. Acesso em 26 set. 2020

SENHORAS, Eloi Martins. NOVO CORONAVÍRUS E SEUS IMPACTOS ECONÔMICOS NO MUNDO. Boletim de Conjuntura (BOCA), Boa Vista, v. 1, n. 2, p. 39-42, feb. 2020. ISSN 2675-1488. Disponível em: https://revista.ufrr.br/boca/article/view/Coronavirus. Acesso em: 25 set. 2020.

15 MINUTOS - GAZETA DO POVO: "Brasil não pode parar": Bolsonaro e a polêmica campanha contra a quarentena total. Locução: Márcio Miranda. Apresentação: Fernando Martins. Curitiba: Estúdio Gazeta do Povo, 27 mar. 2020. Podcast. Disponível em https://www.gazetadopovo.com.br/republica/bolsonaro-campanha-quarentena/. Acesso em 19 set. 2020 